Научная статья

УДК 347.5

https://doi.org/10.24866/1813-3274/2021-3/140-152

\title{
ОБЯЗАТЕЛЬСТВА, ВОЗНИКАЮЩИЕ ИЗ ДЕЙСТВИЙ В ЧУЖИХ ИНТЕРЕСАХ БЕЗ ПОРУЧЕНИЯ: ПОНЯТИЕ, ЮРИДИЧЕСКАЯ ПРИРОДА, ПРАКТИКА ПРИМЕНЕНИЯ
}

\author{
Г. Н. Шевченко ${ }^{1}$, Дальневосточный федеральный университет, \\ г. Владивосток, Россия \\ E-mail: shevchenko.gn@dvfu.ru
}

Аннотащุия. В статье рассматриваются проблемы понятия и юридической природы обязательства, возникающего из действий в чужом интересе без поручения, которое автор определяет как внедоговорное и охранительное, в рамках которого реализуются меры защиты. Автор исследовал историю возникновения обязательств, возникающих из действий в чужих интересах без поручения, известных ещё со времён римского права, но получивших должное законодательное закрепление только в действующем Гражданском кодексе Российской Федерации. Действия в чужом интересе без поручения подразделяются на фактические, признаваемые юридическими поступками, и юридические, которые автором квалифицируются как сделки. К фактическим действиям в чужом интересе без поручения относятся и действия, совершаемые в целях спасания жизни и (или) здоровья гражданина, о необходимости правового регулирования которых, а также обязательств, из них возникающих, неоднократно упоминалось ещё в советской цивилистической литературе. На основе анализа судебной практики рассматриваются условия, которым должны соответствовать действия в чужом интересе без поручения, необходимые для возникновения рассматриваемого обязательства. В статье делается вывод, что одобрение действий действующего лица (гестора) заинтересованным лицом (доминусом) преобразует внедоговорное охранительное обязательство в договорное регулятивное. При этом одобрение действий гестора рассматривается в статье как односторонняя сделка, одностороннее волеизъявление доминуса. Обязанности доминуса по возмещению понесённых гестором убытков существуют независимо от одобрения или неодобрения им предпринятых гестором действий, а также независимо от того, достигнут или не достигнут положительный результат. Отмечается,

\footnotetext{
${ }^{1}$ Галина Николаевна Шевченко, доктор юридических наук, профессор кафедры гражданского права и процесса Юридической школы Дальневосточного федерального университета, г. Владивосток, Россия.

(C) Шевченко Г. Н., 2021
} 
Шевченко Г. Н. Обязательства, возникающие из действий в чужих интересах без поручения: понятие, юридическая природа, практика применения

что неодобрение доминусом предпринятых гестором действий влечёт за собой отказ в возмещении гестору понесённых им расходов и иного реального ущерба только на будущее время в отношении действий, которые будут совершены уже после их неодобрения.

Ключевые слова: действия в чужом интересе без поручения; ведение чужих дел без поручения; охранительное внедоговорное обязательство; регулятивное внедоговорное обязательство; спасание жизни и имущества; заключение сделки; преобразование обязательства; альтруистические действия; кондикционные обязательства; правомерные действия; действующее лицо; заинтересованное лицо; гестор; доминус; односторонние обязательства; одобрение действий; меры защиты; меры ответственности.

Для цุитирования: Шевченко Г. Н. Обязательства, возникающие из действий в чужих интересах без поручения: понятие, юридическая природа, практика применения // Азиатско-Тихоокеанский регион: экономика, политика, право. 2021. № 3. C. 140-152. https://doi.org/10.24866/1813-3274/2021-3/140-152.

Original article

\section{OBLIGATIONS ARISING FROM AGENCY OF NECESSITY: THE CONCEPT, LEGAL NATURE, PRACTICE OF APPLICATION}

Galina N. Shevchenko ${ }^{1}$, Far Eastern Federal University, Vladivostok, Russia E-mail: shevchenko.gn@dvfu.ru

Abstract. In the article the author considers the problems of the concept and legal nature of the obligation arising from agency of necessity, which the author defines as a noncontractual and protective one, within the framework of which protective measures are realized. The author has studied the history of creation of obligations arising from agency of necessity that have been known since the time of Roman law but have received due legislative consolidation only in the effective Civil Code of the Russian Federation. Acts of an agent of necessity can be divided into physical ones, recognized as legal acts, and juridical ones, which the author qualifies as transactions. Physical acts for the benefit of others without their authorization include acts performed in order to save the life and (or) health of a person, the need for legal regulation of which, as well as the obligations arising from them, has been repeatedly emphasized in the Soviet civil literature. Based on the analysis of judicial practice, the conditions with which the agency of necessity shall com-

\footnotetext{
${ }^{1}$ Galina N. Shevchenko, Doctor of Law, Professor of Faculty of Civil Law and Process in the School of Law, Far Eastern Federal University, Vladivostok, Russia.
} 
ply in order for the obligation being considered to emerge are investigated. The author comes to the conclusion that the approval of the acts of an acting person (gestor) by an interested person (dominus) transforms the non-contractual protective obligation into a contractual regulatory one. At the same time, approval of the gestor's actions is considered in the article as a unilateral transaction, a unilateral expression of the dominus's will. The obligations of the dominus to compensate damages suffered by the gestor exist regardless of the approval or disapproval of the gestor's actions as well as of achievement of a positive result. It has been noted that disapproval of the gestor's actions by the dominus entails a refusal to reimburse the gestor for the costs incurred and other actual damage only for the future in relation to actions that will be committed after their disapproval.

Keywords: agency of necessity; conducting affairs of others without their authorization; protective non-contractual obligation; regulatory non-contractual obligation; life and property saving; conclusion of a deal; transformation of obligation; altruistic actions; unjust enrichment obligations; lawful actions; acting person; interested person; gestor; dominus; unilateral obligations; approval of actions; protective measures; liability.

For citing: Obligations arising from agency of necessity: the concept, legal nature, practice of application // PACIFIC RIM: Economics, Politics, Law. 2021. No. 3. P. 140152. https://doi.org/10.24866/1813-3274/2021-3/140-152.

В юридической литературе называются различные виды внедоговорных обязательств. Традиционно в учебниках по гражданскому праву к ним относят деликтные и кондикционные обязательства. В последнее время кроме деликтных и кондикционных обязательств к внедоговорным обязательствам добавляют ещё и обязательства из односторонних действий, включая в них публичное обещание награды, обязательства из публичного конкурса и обязательства из действий в чужом интересе без поручения.

При этом обычно виды внедоговорных обязательств и виды охранительных обязательств считаются совпадающими, иногда они даже отождествляются, с чем категорически нельзя согласиться, поскольку при выделении внедоговорных и охранительных обязательств используются разные критерии классификации, в первом случае - это основания их возникновения, во втором - осуществляемые обязательствами функции, вследствие чего виды охранительных обязательств гораздо многочисленнее видов внедоговорных обязательств. Деликтные и кондикционные обязательства, вне всякого сомнения являющиеся одновременно и внедоговорными, и охранительными, неоднократно исследовались в юридической литературе. Обязательствам из односторонних действий (сделок), в этом плане, повезло гораздо меньше, поэтому многие вопросы не получили должного рассмотрения и продолжают вызывать споры. Что касается таких обязательств из односторонних сделок, 
Шевченко Г. Н. Обязательства, возникающие из действий в чужих интересах без поручения: понятие, юридическая природа, практика применения

как обязательства из публичного обещания награды и публичного конкурса, то они носят регулятивный характер. В настоящее время в юридической литературе высказано мнение, что наряду с внедоговорными охранительными обязательствами существует ещё и категория «внедоговорных регулятивных обязательств», к которым, по мнению украинского цивилиста В. Н. Игнатенко, можно отнести публичное обещание вознаграждения (без объявления конкурса и по результатам конкурса); совершение действий в имущественных интересах другого лица без его поручения и ещё ряд обязательств [1]. Представляется, что следует согласиться с высказанным мнением о существовании регулятивных внедоговорных обязательств, к числу которых в российском законодательстве следует отнести обязательства из публичного обещания награды и обязательства из публичного конкурса. В то же время, ещё один вид обязательств из односторонних действий - обязательство из действий в чужих интересах без поручения, анализу которого и будет посвящена данная статья, с нашей точки зрения, не является регулятивным, а относится к охранительным обязательствам. В рамках охранительных обязательств могут реализовываться как меры защиты, так и меры ответственности, поскольку обязательства из действий в чужих интересах без поручения носят правомерный характер, то они относятся к мерам защиты. Таким образом, следует признать, что обязательства из действий в чужих интересах без поручения являются внедоговорными охранительными обязательствами, в рамках которых реализуются меры защиты.

Обязательства, возникающие из действий в чужих интересах без поручения, известны со времен римского права, в котором их относили к квазиконтрактам. И. Б. Новицкий отмечал, что, обозначив такие обязательства как квази-договорные, римские юристы делали выводы о том, что спорные вопросы об условиях и ответственности сторон разрешаются аналогично тому, как они разрешаются применительно к соответствующим договорам [2, с. 209]. В Российской Империи этот вид обязательств не получил законодательного оформления. Только в проекте Гражданского уложения появились нормы, посвященные ведению чужих дел без поручения, где его участники получили специфичные наименования «хозяин» и «распорядитель», однако проект так и не получил силу закона. В Гражданских кодексах РСФСР 1922 и 1964 гг. и в Основах гражданского законодательства 1961 г. эти обязательства не регламентировались. В. А. Рясенцев отмечал, что «в советском законодательстве обязательству из ведения дела другого лица без поручения не посвящено ни одной статьи» [3, с. 549], и ещё в 1946 г. предложил детальную регламентацию ведения чужого дела без поручения. Впервые законодательное закрепление обязательства из действий в чужих интересах без поручения получили только в Основах гражданского законодательства Союза ССР и республик 1991 г., содержащих всего лишь одну (118) статью, посвящённую им. Развёрнутое правовое регулирование эти обязательства получили только с принятием Части второй Гражданского 
кодекса РФ, глава 50 которого так и называется «Действия в чужом интересе без поручения». Стоит обратить внимание, что эта глава находится сразу за главой 49, посвящённой договору поручения, подчёркивая ещё раз зависимый характер этих обязательств. «Действия без поручения, иного указания или заранее обещанного согласия заинтересованного лица в целях предотвращения вреда его личности или имуществу, исполнения его обязательств или в иных непротивоправных интересах (действия в чужих интересах без поручения) должны совершаться исходя из очевидной выгоды или пользы и действительных или вероятных намерений заинтересованного лица и с необходимой по обстоятельствам заботливостью и осмотрительностью» (ст. 980 ГК РФ). Такое определение позволяет признать, что в настоящее время законодатель, называя эти отношения действиями в чужом интересе без поручения, отказался от использования традиционного термина «ведение чужих дел», включил в них два вида отношений: отношения, связанные с совершением фактических действий, направленных на предотвращение вреда личности или имуществу, и традиционное ведение чужих дел без поручения, когда действующее лицо совершает сделки в интересах другого лица.

Определение действий в чужих интересах без поручения в ст. 980 ГК РФ не содержит обязательства, и (по верному замечанию казахского учёного С. И. Климкина, а Гражданский кодекс Республики Казахстан включает аналогичное российскому законодательству определение) такое конструирование главы, посвящённой этому виду обязательств, способно привести к неверному пониманию его существа и могут даже привести к неверному выводу, что обязанным лицом выступает лицо, действовавшее в чужих интересах, то есть гестор [4]. Традиционно первая по порядку статья любой главы Гражданского кодекса РФ посвящена понятию обязательства, объясняющему его сущность, а первые статьи в соответствующих главах ГК РФ и ГК Республики Казахстан, посвящённые действиям в чужих интересах без поручения, построены по другому принципу. В ГК РФ такая регламентация отношений в обязательствах из действий в чужих интересах без поручения особенно упречна, поскольку глава 50, посвященная им, находится в разделе, регламентирующем договорные отношения, в котором каждый вид договорных обязательств начинается с их определения. Системное же толкование норм главы 50 ГК РФ в целом однозначно позволяет утверждать, что в качестве кредитора в обязательстве из действий в чужих интересах без поручения выступает лицо, действующее в чужом интересе, - гестор, действия которого должны отвечать установленным в законе условиям. В качестве должника выступает заинтересованное лицо - то лицо, в интересах которого предпринимаются действия, именуемое ещё в римском праве доминусом. М. И. Брагинский придерживался иного мнения, отмечая, что со времен римского права «главными были признаны обязанности именно гестора, а доминуса побочными... Подобную оценку соотношения обязанностей сторон можно 
Шевченко Г. Н. Обязательства, возникающие из действий в чужих интересах без поручения: понятие, юридическая природа, практика применения

считать в определённой мере присущей и современному праву» [5, с. 390]. Представляется, что с такой характеристикой рассматриваемых обязательств нельзя согласиться. У гестора нет и не может быть обязанности совершить действия, предусмотренные в ст. 980 ГК РФ, он их совершает исключительно по собственной инициативе, в большинстве случаев исходя из альтруистических мотивов. Действительно, эти действия должны отвечать определённым условиям, установленным в ГК РФ, но такая их регламентация установлена потому, что они порождают внедоговорное обязательство в отсутствии возможности согласования воли сторон. Другие обязанности гестора (уведомление о совершённых действиях, предоставление отчёта о них) носят характер кредиторских обязанностей, и их наличие не может привести к выводу, что обязанности гестора в обязательстве являются главными, поскольку обязательство из действий в чужих интересах без поручения направлено на возмещение доминусом реальных убытков и иных расходов, понесённых гестором. Именно в этом и заключается смысл этого обязательства.

Особый интерес вызывает определение юридической природы обязательства, возникающего из действий в чужих интересах без поручения. Традиционно действия в чужом интересе рассматриваются как односторонние сделки. Вместе с тем высказаны и иные позиции. Так, М. К. Сулейменов полагает, что действия гестора направлены не на возмещение ему понесённых убытков или ущерба, а на предотвращение вреда имуществу или личности доминуса, поэтому такие действия он предлагает признать не юридическими актами, к которым относятся сделки, а юридическими поступками [6, с. 46]. Представляется, что действия в чужих интересах могут быть и юридическими поступками, и сделками. Действия в чужом интересе без поручения могут быть фактическими, направленными на предотвращение вреда личности или имуществу другого лица, и тогда они являются юридическими поступками, порождающими внедоговорные обязательства, но кроме фактических действий, направленных на предотвращение вреда личности или имуществу другого лица, гестор в интересах доминуса без его поручения может совершать и сделки, влекущие квазидоговорные обязательства. В. А. Рясенцев писал, что «следует различать два вида юридических действий гестора: 1) действия по отношению к третьим лицам, в частности, сделки, совершаемые при ведении чужого дела; 2) действия, совершаемые непосредственно по отношению к заинтересованному лицу (доминусу): последние имеют место, когда гестор лично и самостоятельно выполняет дело, не вступая для этой цели в гражданские правоотношения с третьими лицами» [3, с. 565]. Таким образом, следует признать, что действия гестора могут быть и сделками, и юридическими поступками. Что касается определения юридической природы возникающих из них обязательств, то здесь следует согласиться с М. И. Брагинским, который при определении, к какому виду из четырёх видов обязательств - договорным, деликтным, квазидоговорным или квазиделиктным следо- 
вало бы их отнести, без сомнения вынес указанные обязательства за рамки договорных, но вместе с тем поставил их рядом, т.е. отнёс к числу квазидоговорных [5, с. 380]. При этом следует оговориться, что фактические действия гестора, направленные на предотвращение вреда личности или имуществу доминуса, обусловливают возникновение квазиделиктных обязательств.

Законодательство устанавливает условия, которым должны отвечать действия гестора, необходимые для возникновения обязательства по возмещению понесённых им убытков и иных расходов.

Прежде всего, такие действия должны осуществляться по инициативе действующего лица, «без поручения, иного указания или заранее обещанного согласия заинтересованного лица». На гестора не может возлагаться обязанность по совершению таких действий, поэтому нормы о действиях в чужих интересах без поручения не применимы при охране наследства, при охране прав несовершеннолетних, иных недееспособных их законными представителями, а также не применимы к действиям государственных и муниципальных органов, для которых такие действия являются одной из целей деятельности, например, действия пожарной охраны. Не имеет значения, по каким мотивам лицо осуществило действия в чужих интересах без поручения. Еще в 1880 г. Ю. С. Гамбаров отнёс действия в чужом интересе к альтруистическим действиям, предполагающим всегда более или менее значительное пожертвование личным трудом, но не имуществом [7, с. 75-76]. Представляется, что именно альтруистические мотивы в большинстве случаев и побуждают гестора совершить действия, направленные на предотвращение вреда личности или имуществу заинтересованного лица. Такие действия являются необходимыми, направленными на предотвращение опасности имуществу, личности, носят неотложный характер, без совершения которых существенно бы пострадали интересы заинтересованного лица. Действующее лицо должно осознавать, что оно действует не в своих, а в чужих интеpecax, «его воля была направлена на доставление пользы, он сознательно заботился о деле другого лица» [3, с. 553]. Поэтому законодатель устанавливает правило, что если действия, непосредственно не направленные на обеспечение интересов другого лица, в том числе в случае, когда совершившее их лицо ошибочно предполагало, что действует в своём интересе, привели к неосновательному обогащению другого лица, применяются правила главы 60 (ст. 987 ГК РФ). Так, суд не признал действиями в чужом интересе без поручения действия истцов по организации выполнения ремонта с заключением договора подряда с третьим лицом для устранения протечки канализационных труб, относящихся к общедомовому имуществу. ЖСК, в зоне ответственности которого находились эти трубы, не осуществлял ремонт аварийных труб, в результате протечки которых постоянно причинялся ущерб имуществу истцов. Суд правильно указал, что у лица, совершающего действия в чужом интересе без поручения, по смыслу законоположений ГК РФ отсутствует собственный интерес в совер- 
Шевченко Г. Н. Обязательства, возникающие из действий в чужих интересах без поручения: понятие, юридическая природа, практика применения

шении таких действий; в рассматриваемом же деле истцы организовали осуществление ремонта с целью прекращения повреждения их имущества, то есть у них был интерес в обеспечении сохранности имущества, принадлежащего им на праве собственности (решение № 2-3258/2017-М-2799/2017 от 30 ноября 2017 г. по делу № 2-3258/2017 Заельцовского районного суда г. Новосибирска). Верховный Суд в Обзоре судебной практики указал, что по смыслу данной нормы лицо, совершившее действия в чужом интересе, должно осознавать, что действия направлены на обеспечение интересов другого лица, а основной целью лица, совершившего действия в чужом интересе, должно являться улучшение положения другого лица, а не его собственного (обзор судебной практики Верховного Суда РФ № 3 (2018) от 14 ноября 2018). Таким образом, в качестве критерия разграничения обязательств из действий в чужом интересе без поручения и кондикционных обязательств выступает именно намерение действующего лица.

Совершаемые гестором правомерные действия должны быть направлены на достижение обозначенных в законе целей: предотвращение вреда личности или имуществу заинтересованного лица, исполнения его обязательств или в иных непротивоправных интересах. Такая регламентация действий в чужих интересах позволяет признать, что сюда подпадают и действия, совершаемые в целях спасания жизни и (или) здоровья гражданина, о необходимости существования которых неоднократно упоминалось ещё в советской юридической литературе. Российский законодатель обязанность по возмещению такого вреда (при наличии всех остальных условий) возложил на заинтересованное лицо, то есть на гражданина, жизни и (или) здоровью которого угрожала реальная опасность. Стоит обратить внимание, что Гражданский кодекс Украины (ст. 1161) реализовал предложения советских цивилистов и обязанность по возмещению такого вреда в полном объёме возложил на государство [8], а не на лицо, в интересах которого осуществлялись такие действия. Регламентация рассматриваемых отношений в российском законодательстве позволяет признать, что действующее лицо может осуществлять действия по вмешательству не только в имущественные отношения доминуса, но и осуществлять действия, направленные на охрану личных неимущественных отношений последнего, например, совершать действия, направленные на спасание жизни, охрану личной неприкосновенности; однако обязательство всегда возникает по поводу возмещения понесённых при этом убытков, расходов, то есть носит имущественный характер.

Действия должны совершаться исходя из очевидной выгоды или пользы и действительных или вероятных намерений заинтересованного лица. По одному из дел суд отказал в удовлетворении требований истца, требовавшего возместить понесённые им на охрану объектов мельничного комплекса расходы, поскольку истец не доказал необходимость в дорогостоящей охране монолитных железобетонных сооружений весом в несколько тысяч тонн (постановление Федерального арбитраж- 
ного суда Волго-Вятского округа от 11 декабря 2001г. по делу № А29-4162/01-2Э). Исключения из этого правила предусмотрены в п. 2 ст. 983 ГК РФ, когда гестор может действовать вопреки желанию и воле заинтересованного лица. Во-первых, это действия с целью предотвращения опасности для жизни лица, попавшего в опасное положение, например, по предотвращению суицида. Во-вторых, исполнение обязанности по содержанию кого-либо против воли того, на ком лежит такая обязанность, например, уплата алиментов на содержание детей.

И наконец, такие действия должны совершаться с необходимой по обстоятельствам дела заботливостью и осмотрительностью, поскольку несоблюдение этого правила влечёт за собой ответственность в форме возмещения причинённого заинтересованному лицу вреда, то есть деликтные обязательства, в которых действия причинителя уже носят противоправный характер, что исключено для действий в чужом интересе без поручения, которые всегда должны быть правомерными. При этом следует учитывать, что такой вред может причиняться и в состоянии крайней необходимости для устранения опасности, угрожающей заинтересованному лицу, поэтому здесь возмещение вреда осуществляется в соответствии со ст. 1067 ГК РФ, устанавливающей особые правила возмещения вреда лицом, причинившим вред, или третьим лицом, в интересах которого действовал причинитель. С учётом обстоятельств причинения вреда суд может освободить этих лиц от возмещения вреда полностью или частично.

Необходимо признать, что действия в чужих интересах должны совершаться лишь при соблюдении этих требований и, как верно указал в своём решении арбитражный суд Республики Марий Эл, «действия в чужом интересе, порождающие юридический результат, должны совершаться не по произвольному желанию любого лица, а лишь с соблюдением установленных законом требований» (решение арбитражного суда Республики Марий Эл от 9 декабря 2019 по делу № А382647/2019). Только отвечающие этим условиям действия в чужом интересе без поручения способны породить рассматриваемые обязательства. В то же время ГК РФ не содержит каких-то иных дополнительных требований к действиям, совершаемым гестором. Поэтому нельзя согласиться с постановлением суда, отказавшего в удовлетворении требований истца - предприятия, заключившего договор подряда с третьим лицом, с целью устранения аварии, действуя при этом в интересах ответчика - управляющей компании. Суд, квалифицируя действия предприятия как действия в чужом интересе без поручения, верно отметил, что истец, привлекая стороннюю организацию, действовал в интересах ответчика, состоящих в том, чтобы ликвидировать аварийную ситуацию как можно быстрее и не допустить причинения вреда третьим лицам, что повлекло бы возникновение у ответчика дополнительных убытков. В то же время суд отказал в удовлетворении требований истца, поскольку последний не представил доказательств обращения к ответчику с прось- 
Шевченко Г. Н. Обязательства, возникающие из действий в чужих интересах без поручения: понятие, юридическая природа, практика применения

бой о разрешении ему принять меры к ликвидации аварийной ситуации (постановление арбитражного Суда Волго-Вятского округа от 3 декабря 2019 г. по делу № А 82-22975/ 2018). ГК РФ не предъявляет такого условия к совершению действий в чужом интересе без поручения. Более того, наличие такого разрешения означает отсутствие обязательства из действий в чужом интересе без поручения, а свидетельствует о том, что обязательство приобрело договорный характер.

Лицо, совершившее действие в чужом интересе без поручения, должно немедленно сообщить об этом заинтересованному лицу и выждать в течение разумного срока его решение об одобрении или неодобрении предпринятых действий. Одобрение рассматривается как односторонняя сделка, односторонне волеизъявление заинтересованного лица, которое обязано возместить гестору необходимые расходы и иной реальный ущерб. Причём такие обязанности заинтересованного лица существуют независимо от одобрения или неодобрения им предпринятых гестором действий, а также независимо от того, достигнут или не достигнут предполагаемый (положительный) результат. Единственным ограничением в размере возмещения является то, что в случае предотвращения ущерба имуществу другого лица, размер возмещения не должен превышать стоимость этого имущества. Неодобрение предпринятых действий заинтересованным лицом влечёт за собой отказ в возмещении гестору понесённых им расходов и иного реального ущерба лишь на будущее время в отношении действий, которые будут совершены уже после их неодобрения; после неодобрения действий гестора у доминуса в дальнейшем не возникает никаких обязанностей ни в отношении совершающего их, ни в отношении третьих лиц. Таким образом, следует признать, что изначально обязательство из совершения фактических действий в чужом интересе без поручения (действий по спасанию чужого имущества или жизни) возникает независимо от воли доминуса и носит внедоговорный характер. Но после уведомления доминуса о совершении действия в его интересах последующее развитие обязательства осуществляется только по его воле. В случае одобрения доминусом действий гестора в дальнейшем к отношениям сторон применяются правила о договоре поручения или ином договоре, соответствующем характеру предпринятых действий, то есть одобрение доминуса преобразует внедоговорное обязательство из действий в чужом интересе без поручения в договорное обязательство сответствующего вида. «Обязательства по возмещению спасавшему лицу понесённых им расходов существуют лишь до момента одобрения совершённых действий заинтересованным лицом. После получения такого одобрения, в том числе и устного, юридическая природа рассматриваемого отношения меняется - согласно ст. 982 ГК они становятся договорными» [9, с. 1064]. М. И. Брагинский отмечал, что «нормальное развитие внедоговорного обязательства, возникшего в чужом интересе без поручения, предполагает трансформацию его в договорное обязательство, построенное по одной из предусмотренных в ГК моделей» [5, с. 381]. В юридической литературе бы- 
ло высказано и иное мнение, в частности, С. И. Климкин указывает, что в случае, когда заинтересованному лицу не отказывают в выплате соответствующего возмещения, отношения сторон становятся договорными, а обязательство из действий в чужом интересе без поручения не возникает [4, с. 388]. Представляется, что с таким толкованием законодательства нельзя согласиться, поскольку договор поручения или иной договор применяются к дальнейшим, к будущим отношениям, а ранее возникшие отношения и есть обязательства из действий в чужих интересах в чистом виде. Согласившись с мнением С. И. Климкина, нам придется признать, что до одобрения действий доминусом стороны вообе не состоят в обязательственных отношениях. Законодатель потому и установил императивные и достаточно жёсткие требования к действиям гестора, чтобы они могли обусловить возникновение внедоговорного обязательства из действий лица в чужих интересах без поручения, то есть при отсутствии соглашения между ними.

Если же лицо совершит в чужих интересах сделку, не имея на то полномочий, то при последующем одобрении сделки заинтересованным лицом оно и становится участником этой сделки, то есть одобрение такой сделки доминусом имеет обратное действие. К этому лицу с соблюдением всех правил об уступке требований и о переводе долга переходят права и обязанности по такой сделке. Так, Верховный Суд РФ в своём определении по конкретному делу указал, что гражданин Л., действуя в непротивоправных интересах гражданки Г., исходя из очевидной пользы для неё и её действительных намерений, заключил соглашение с адвокатом для представления интересов Г. в суде, то есть совершил действия в чужом интересе. Тот факт, что адвокат после заключения с ним соответствующего соглашения представлял интересы Г., участвуя вместе с ней в судебных заседаниях, свидетельствует о том, что Г. фактически одобрила заключённое Л. и адвокатом соглашение о представлении последним её интересов в суде. При таких обстоятельствах в силу положений статьи 982 ГК РФ данные отношения следует квалифицировать как вытекающие из договора поручения. У лица, одобрившего совершённые без поручения в его интересах действия, возникает обязанность возместить совершившему такие действия лицу, как поверенному, понесённые им издержки (определение судебной коллегии по гражданским делам Верховного Суда РФ от 7 февраля 2017 г. № 83- КГ16-15). Кроме одобрения заинтересованного лица для его участия в сделке требуется согласие кредитора в возникшем обязательстве, если только последний уже в момент заключения сделки не знал и не должен был знать о её совершении в чужом интересе. При отсутствии согласия доминуса принять на себя права и обязанности по заключенной сделке у гестора сохраняется право на взыскание ранее понесенных расходов, если его действия отвечают условиям, установленным в ст. 980 ГК РФ. Если же действия гестора не отвечают этим условиям, например, он действует вопреки известной ему воле заинтересованного лица, то гестор лишается 
Шевченко Г. Н. Обязательства, возникающие из действий в чужих интересах без поручения: понятие, юридическая природа, практика применения

права на возмещение понесенных расходов и самостоятельно отвечает перед третьими лицами по заключённой им сделке.

Кроме возмещения необходимых расходов и иного реального ущерба на доминуса может быть возложена обязанность выплаты вознаграждения гестору за совершённые им действия, но не во всех случаях, а при наличии двух условий: если действия привели к положительному результату для заинтересованного лица, и если такое право предусмотрено законом, соглашением с заинтересованным лицом или обычаями делового оборота (ст. 985 ГК РФ).

Подводя итог вышеизложенному, следует признать, что обязательство из действий в чужом интересе без поручения является внедоговорным охранительным обязательством, направленным на возмещение понесённых действующим лицом (гестором) реального ущерба и иных расходов, возникших в результате его действий, предпринятых в целях предотвращения вреда личности или имуществу, исполнения обязательств или в иных непротивоправных интересах заинтересованного лица (доминуса), которое в случае одобрения действий последним преобразуется в дальнейшем в договорное регулятивное обязательство, соответствующее предпринятым гестором действиям.

\section{Список литературы}

1. Игнатенко В. Н. Самозащита как основание возникновения внедоговорных обязательств // Обязательства, возникающие не из договора : сборник статей / отв. ред. М. А. Рожкова. - Москва : Статут, 2015. - С. 23-33.

2. Новицкий И. Б. Римское право : учебник. - Москва : Моск. гос. ун-т, Юрид. фак., 1994. - 245 с.

3. Рясенцев В.А. Лекция на тему «Ведение чужих дел без поручения» // Представительство и сделки в современном гражданском праве. - Москва : Статут, 2006. - С. 549-578.

4. Климкин С. И. Обязательства из действий в чужом интересе без поручения по законодательству Республики Казахстан // Внедоговорные обязательства : Материалы междунар. науч.-практ. конф. / отв. ред. М. К. Сулейменов. - Алматы, 2017. - С. 386-388.

5. Брагинский М. И., Витрянский В. В. Договорное право. Книга третья. Договоры о выполнении работ и оказании услуг. - Москва : Статут, 2005. - 1055 с.

6. Сулейменов М.К. Внедоговорные обязательства по законодательству Республики Казахстан // Внедоговорные обязательства : Материалы междунар. науч.- практ. конф. / отв. ред. М. К. Сулейменов. - Алматы, 2017. - С. 14-50.

7. Гамбаров Ю. С. Добровольная или безвозмездная деятельность в чужом интересе: Социологические исследование института neg. Gestio (добровольное ведение дел). - Москва : ЛЕНАНД, 2017. - 168 с. 
8. Кузнецова Н. С. Регулирование внедоговорных обязательств в гражданском законодательстве Украины // Внедоговорные обязательства: Материалы междунар. науч.- практ. конф. /отв. ред. М. К. Сулейменов. - Алматы, 2017. - С. 63-67.

9. Российское гражданское право : учебник : в 2 т. / отв. ред. Е. А. Суханов. Москва : Статут, 2010. - Т. 2: Обязательственное право. - 1208 с.

\section{References}

1. Ignatenko, V. N. 2015. "Self-defense as the basis for creation of non-contractual obligations." (In Russian). Obligations arising not from the contract: a collection of articles. Edited by M. A. Rozhkova. - Moscow: Statute. 23-33.

2. Novitsky, I. B. Roman law: textbook. (In Russian). - Moscow: Moscow State University, Law Faculty, 1994.

3. Ryasentsev, V. A. 2006. Lecture on the topic "Agency of necessity". (In Russian). Representation and transactions in modern civil law. - Moscow: Statute. 549-578.

4. Klimkin, S. I. 2017. "Agency of necessity under the legislation of the Republic of Kazakhstan." (In Russian). Non-contractual obligations: Materials of international research and training conference. Edited by M. K. Suleimenov. - Almaty. 386-388.

5. Braginsky, M. I., Vitryansky, V. V. Contract law. Book three. Contract for the performance of work and rendering of services. (In Russian). - Moscow: Statute, 2005.

6. Suleimenov, M. K. 2017. "Non-contractual obligations under the legislation of the Republic of Kazakhstan." (In Russian). Non-contractual obligations: Materials of international research and training conference. Edited by M. K. Suleimenov. - Almaty. 14-50.

7. Gambarov, Yu. S. Voluntary or gratuitous activity for the benefit of others: Sociological research of the institute neg. Gestio (voluntary agency). (In Russian). - Moscow: LENAND, 2017.

8. Kuznetsova, N. S. 2017. "Regulation of non-contractual obligations in the civil legislation of Ukraine." (In Russian). Non-contractual obligations: Materials of international research and training conference. Edited by M. K. Suleimenov. - Almaty. 63-67.

9. Sukhanov, E. A., ed. Russian civil law. Vol. 2. Law of obligations (In Russian). Moscow: Statute, 2010. 